PAPER

\title{
When is Onuf's nucleus involved in multiple system atrophy? A sphincter electromyography study
}

\author{
T Yamamoto, R Sakakibara, T Uchiyama, Z Liv, T lto, Y Awa, K Yamamoto, M Kinou, T Yamanishi, \\ T Hattori
}

J Neurol Neurosurg Psychiatry 2005;76:1645-1648. doi: 10.1136/jnnp.2004.061036

See end of article for authors' affiliations

......................

Correspondence to:

Dr Ryuji Sakakibara,

Neurology Department,

Chiba University, 1-8-1

Inohana Chuo-ku, Chiba

260-8670, Japan;

sakakibara@faculty.

chiba-u.jp

Received

13 December 2004

In revised form

11 May 2005

Accepted 12 May 2005

\begin{abstract}
Background: External anal sphincter (EAS) electromyography (EMG) abnormalities can distinguish multiple system atrophy (MSA) from Parkinson's disease in the first five years after disease onset. However, the prevalence of the abnormalities in the early stages of MSA is unknown.
\end{abstract}

Objectives: To present EAS-EMG data in the various stages of MSA.

Methods: 84 patients with "probable" MSA were recruited (42 men, 42 women; mean age 62 years (range 47 to 78$)$; mean disease duration 3.2 years $(0.5$ to $8.0 ;<1$ year in $25 \%) ; 50$ cerebellar form (MSA-C), 34 parkinsonian form (MSA-P)). EAS motor unit potential (MUP) analysis and EMG cystometry were carried out in all patients.

Results: The overall prevalence of neurogenic change of the EAS MUP was $62 \%-52 \%$ in the first year after disease onset, increasing to $83 \%$ by the fifth year $(p<0.05)$; it also increased with severity of gait disturbance $(p<0.05)$, storage and voiding disorders, and detrusor sphincter dyssynergy (NS). The neurogenic change was not correlated with sex, age, MSA-P/C, postural hypotension, constipation, erectile dysfunction in men, underactive or acontractile detrusor, or detrusor overactivity. In 17 incontinent patients without detrusor overactivity or low compliance, urinary incontinence was more severe in those with neurogenic change than in those without $(p<0.05)$.

Conclusions: Involvement of Onuf's nucleus in MSA is time dependent. Before the fifth year of illness, the prevalence of neurogenic change does not seem to be high, so a negative result cannot exclude the diagnosis of MSA.
$\mathrm{O}$ ne of the distinguishing hallmarks in the pathology of multiple system atrophy (MSA) is neuronal loss in the sacral Onuf's nucleus. ${ }^{1-3}$ Onuf's nucleus plays a key role in urinary continence and the micturition reflex. ${ }^{4}$ Neurones in this nucleus receive not only cortical inputs but also noradrenergic and serotonergic facilitatory inputs by way of interneurones from various brain stem structures, including the pontine urine storage centre. ${ }^{56}$ External anal sphincter (EAS) electromyography (EMG) is an established method for detecting neurogenic change of motor unit potentials (MUP), which reflects denervation and reinnervation of the sphincter muscle. ${ }^{7}$ The significance of the EAS EMG is well known in MSA, ${ }^{7-15}$ and it is reported that EAS MUP abnormalities can distinguish MSA from Parkinson's disease in the first five years after disease onset. ${ }^{7-9}$ However, the prevalence of the abnormalities in the early stages of MSA is unknown. We present our EAS EMG data in the various stages of MSA.

\section{METHODS}

We recruited 84 patients with "probable" MSA ${ }^{16}: 42$ men, 42 women; mean age 62 years (range 47 to 78 ); mean disease duration 3.2 years $(0.5$ to 8.0 years; $<1$ year in 21 patients $(25 \%)) ; 50$ MSA-C (cerebellar form), 34 MSA-P (parkinsonian form). We added an imaging study to ensure the diagnosis of the early cases; all patients had magnetic resonance imaging (MRI) abnormalities including pontocerebellar atrophy, abnormal signal intensity in the cerebellar peduncle, cross sign in the pons, and abnormal signal intensity in the posterolateral putamen, all of which were consistent with MSA and helped to exclude Parkinson's disease and progressive supranuclear palsy. ${ }^{17}$ Genetic analyses were carried out as far as possible to exclude hereditary spinocerebellar ataxia. No patient had abnormalities of blood chemistry (including blood sugar) or urinalysis. None had abnormal findings on digital examination or ultrasound echography of the pelvic organs.

After inserting a concentric needle electrode into the EAS, we carried out single MUP analysis in all patients, using an EMG computer (Neuropack Sigma; Nihon Kohden, Tokyo, Japan). ${ }^{15}$ We sampled at least 10 single MUPs per patient, manually examining the automatically sampled waves to ensure that the MUPs were indeed single. Neurogenic change was diagnosed when at least one of the following abnormalities was seen:

- more than $20 \%$ of MUPs had a duration of $>10 \mathrm{~ms}$;

- the average duration of MUP was $>10 \mathrm{~ms}$, including the late components in particular. ${ }^{14} 18$

We carried out standard EMG cystometry with a pressureflow analysis in all patients. ${ }^{15} 1920$ The filling phase abnormalities include detrusor overactivity and low compliance detrusor. The voiding phase abnormalities include detrusorsphincter dyssynergy. In the Schäfer's nomogram test, ${ }^{20}$ we obtained detrusor contractility classed as strong, normal, weak, or very weak; the latter two were designated as underactive detrusor in this study. The detrusor is classed as acontractile when patients with large post-void residuals (PVR) cannot contract the detrusor at all without urinary flow.

Abbreviations: EAS, external anal sphincter; MSA, multiple system atrophy; MSA-C, cerebellar form of multiple system atrophy; MSA-P, parkinsonian form of multiple system atrophy; MUP, motor unit potential; PVR, post-void residual 


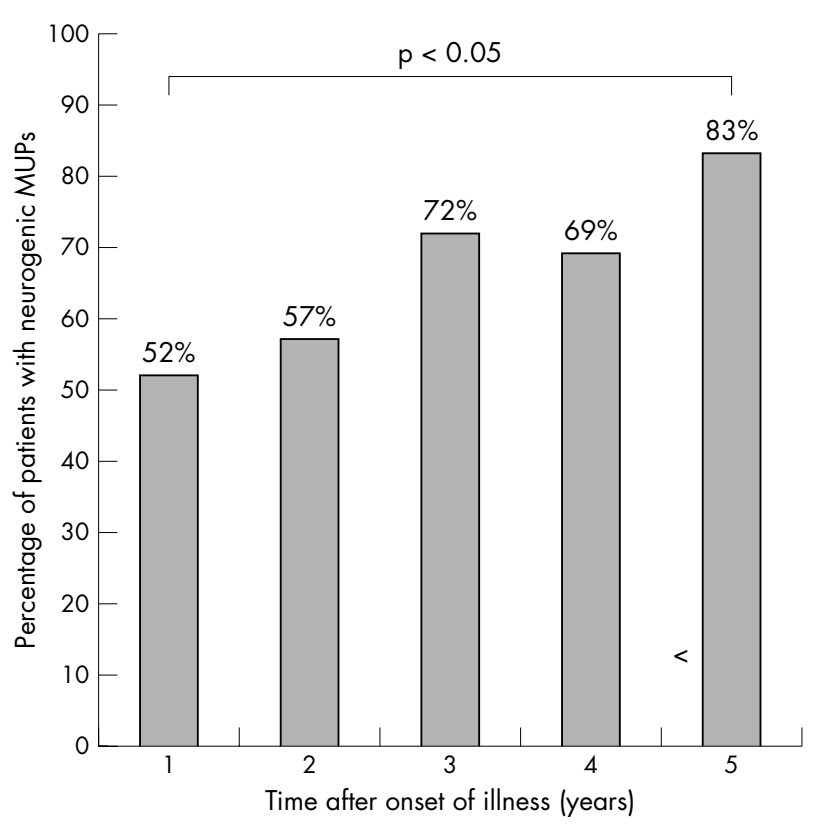

Figure 1 Neurogenic sphincter EMG and duration of illness. The prevalence of neurogenic sphincter EMG increased during a course of illness. MUP, motor unit potential.

All patients gave their informed consent before participating in the study. Statistics were analysed using the $\chi^{2}$ test.

\section{RESULTS}

Patients' functional ability and urinary disorders were as follows. Gait disorder (as measured by the international cooperative ataxia rating scale, walking capacities subscale ${ }^{21}$ ) was absent (score of 0 ) in none, independent walking (score $1-3$ ) in 23, walking with one stick (score 4-5) in 22, walking with aid (score 6-7) in 28 , and wheelchair bound (score 8 ) in 11. All patients except for two had urinary symptoms. Urinary incontinence (storage disorder) was never experienced in 25, monthly in 14, weekly in 13, and daily in 32 . The PVR volume measured by transurethral catheterisation was $<100 \mathrm{ml}$ in $35,100-200 \mathrm{ml}$ in 27 , and $>200 \mathrm{ml}$ in 22 .

The overall prevalence of neurogenic change was $62 \%$ in our patients $-52 \%$ in the first year after disease onset, and $83 \%$ by the fifth year. Thus the prevalence of neurogenic change increased during the course of the illness $(p<0.05)$ (fig 1). Changes in the percentage of MUPs with a duration of more than $10 \mathrm{~ms}$, including patients undergoing repeated studies, are shown in fig 2. Many of the patients who underwent repeated studies had normal to mild abnormality at the initial assessment, and this became marked during the course of the illness, although in two cases the EAS EMG findings remained normal. The prevalence of neurogenic change was $47 \%$ in patients who walked independently, but $82 \%$ in those who were wheelchair bound $(\mathrm{p}<0.05)$ (table 1$)$. Similar but non-significant changes were found for urinary incontinence (59\% of patients without urinary incontinence had neurogenic change $v 63 \%$ with incontinence); post-void residual $(58 \%$ with PVR $<200 \mathrm{ml} v 73 \%$ in those with PVR $>200 \mathrm{ml})$; and detrusor sphincter dyssynergy $(60 \%$ in patients without detrusor sphincter dyssynergy $v 73 \%$ in those with dyssynergy). The neurogenic sphincter EMG results were not clearly correlated with sex, age, MSA-P/C, postural hypotension, constipation, erectile dysfunction in men, underactive or acontractile detrusor, or detrusor overactivity.

Seventeen of the 56 incontinent patients (seven men, 10 women) lacked abnormal bladder contraction during the filling phase, although 12 of the 17 also had PVR (mean $135 \mathrm{ml}$ (range 30 to 500)). In the 17 patients, urinary incontinence was more severe in those with neurogenic change ( $\mathrm{n}=8$; monthly, 0 ; weekly, 1 ; daily, 7$)$ than in those without ( $\mathrm{n}=9$; monthly, 4; weekly, 2; daily, 3$)(\mathrm{p}<0.05)$.

\section{DISCUSSION}

Results of the EAS EMG in over 500 MSA patients have already been reported, with an abnormality rate of more than $70 \%$ in many studies. ${ }^{7-15}$ Compared with those findings, the overall prevalence rate of neurogenic change in the present study was slightly lower $(62 \%)$. This is presumably because up to $25 \%$ of our patients had a disease duration of one year or less, as early referral to our department has increased recently, and patients are able to come to us without referral. Thus the diagnosis of MSA in such early cases should be made with extreme caution. In addition to the clinical diagnostic criteria, ${ }^{16}$ we added an imaging study to ensure the diagnosis in all patients, and we carried genetic analyses as far as possible. Although the EAS MUP abnormalities allow one to distinguish MSA from Parkinson's disease in the first five years after disease onset, ${ }^{7-9}$ the prevalence of the abnormalities in the early stages of MSA (or, conversely, the false negative rate) has not been established up to now. We report here for the first time that in our patient cohort the prevalence of neurogenic change was $52 \%$ in the first year after disease onset, increasing to $83 \%$ by the fifth year $(p<0.05)$. Among the patients who underwent repeated studies, many were normal or had only mild abnormality at the initial examination, but the abnormality became marked during the course of their illness. Therefore, as expected, the involvement of Onuf's nucleus in MSA is time dependent. In the early stages of illness, the prevalence of neurogenic change in MSA does not seem to be high. In two patients who underwent repeated studies, the EAS EMG findings remained normal. We do not know whether there are some

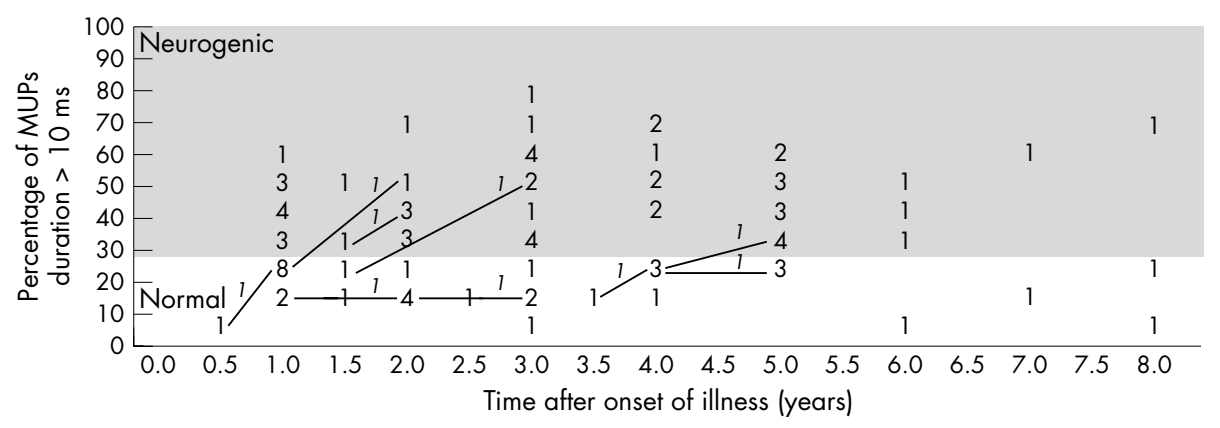

Figure 2 Change in percentage of motor unit potentials (MUPs) of duration $>10 \mathrm{~ms}$ with duration of illness. Roman figures = the number of the patients; italic figures = the number of the patients who underwent repeated study. 
Table 1 Neurogenic sphincter EMG and clinical variables other than duration of illness

\begin{tabular}{|c|c|c|c|c|c|c|}
\hline & \multicolumn{2}{|c|}{$\begin{array}{l}\text { Patients with } \\
\text { neurogenic sphincter } \\
\text { EMG }\end{array}$} & & \multicolumn{2}{|c|}{$\begin{array}{l}\text { Patients with } \\
\text { neurogenic } \\
\text { sphincter EMG }\end{array}$} & \\
\hline & No & $\%$ & & No & $\%$ & \\
\hline Male & $27 / 42$ & 65 & Female & $25 / 42$ & 59 & NS \\
\hline Age $<60$ years & $22 / 39$ & 56 & Age $>60$ years & $30 / 45$ & 66 & NS \\
\hline MSA-C & $29 / 50$ & 58 & MSA-P & $23 / 34$ & 68 & NS \\
\hline Independent walking $\left(1-3^{*}\right)$ & $11 / 23$ & 48 & Wheelchair bound $\left(6-7^{*}\right)$ & $9 / 11$ & 82 & $p<0.05$ \\
\hline Postural hypotension - & $30 / 48$ & 63 & Postural hypotension + & $22 / 36$ & 60 & NS \\
\hline Constipation - & $40 / 66$ & 61 & Constipation + & $12 / 18$ & 67 & NS \\
\hline Erectile dysfunction - & $4 / 5$ & 80 & Erectile dysfunction + & $19 / 30$ & 63 & NS \\
\hline Continent & $15 / 25$ & 59 & Incontinent & $37 / 59$ & 63 & NS \\
\hline $\mathrm{RU}<200 \mathrm{ml}$ & $36 / 62$ & 58 & $\mathrm{RU}>200 \mathrm{ml}$ & $16 / 22$ & 73 & NS \\
\hline Detrusor overactivity - & $14 / 26$ & 55 & Detrusor overactivity + & $38 / 58$ & 65 & NS \\
\hline $\mathrm{UD} / \mathrm{AD}-$ & $29 / 52$ & 56 & $\mathrm{UD} / \mathrm{AD}+$ & $20 / 32$ & 63 & NS \\
\hline DSD - & $44 / 73$ & 60 & $\mathrm{DSD}+$ & $8 / 11$ & 73 & NS \\
\hline
\end{tabular}

MSA patients who never develop neurogenic change during the course of their illness. However, Wenning et al reported three patients with normal EAS EMG and necropsy confirmation of MSA. ${ }^{22}$ Thus the negative result cannot exclude the diagnosis of MSA.

The prevalence of neurogenic change also increased with the severity of gait disturbance $(\mathrm{p}<0.05)$ in the present study. However, it was not related to postural hypotension (reflecting adrenergic nerve dysfunction),${ }^{17}$ erectile dysfunction in men (presumably reflecting cholinergic and nitrate oxidergic nerve dysfunction), ${ }^{23}$ detrusor overactivity (reflecting central type of detrusor dysfunction), ${ }^{12}{ }^{15}$ constipation (presumably reflecting both peripheral and central types of autonomic and somatic dysfunctions), ${ }^{24}$ or sex. Changes in the EAS MUP were slightly more common in patients with detrusor sphincter dyssynergy (reflecting central type of sphincter dysfunction). ${ }^{13}$ It has previously been reported that neurogenic change does not correlate directly with a clinically obvious functional deficit. ${ }^{7}$ Patients with marked abnormalities of the EAS MUP may have no faecal incontinence ${ }^{22}$ although in such patients anal sphincter weakness is not uncommon. ${ }^{24}$ In the present study, the prevalence of neurogenic change slightly increased with the severity of storage disorder (incontinence) and voiding disorder (large PVR). The latter may only reflect a parallel and not a causative relation. In the former, the most common urinary incontinence in MSA is urge incontinence, which mostly results from the detrusor (bladder) overactivity. However, we noted urinary incontinence in 17 patients without detrusor overactivity or a low compliance detrusor, which might have a sphincter aetiology. Urinary incontinence was more severe in the patients with neurogenic change than in those without $(p<0.05)$. These results are in agreement with observations by Beck et al, ${ }^{12}$ and with our previous findings that neurogenic change of the EAS MUP led to a low urethral pressure and sphincter incompetence, particularly in women in the middle to advanced stages of MSA (inability to hold urine, "intrinsic sphincter deficiency", or stress urinary incontinence type 3). ${ }^{25}$ The function of Onuf's nucleus is not confined to the innervation of the EAS-that is, it innervates external urethral sphincter as well. As we do not carry out EMG of the external urethral sphincter routinely, the present study results may represent only one aspect of the nucleus. However, our findings may contribute to the differential diagnosis of parkinsonism and ataxic cerebellar disorders.

In conclusion, the results of the present study suggest that the involvement of Onuf's nucleus in MSA is time dependent.
In the early stages of the illness, the prevalence of neurogenic change does not seem to be high, so a negative result cannot exclude a diagnosis of MSA.

\section{Authors' affiliations}

T Yamamoto, R Sakakibara, T Uchiyama, Z Liu, T Ito, T Hattori,

Department of Neurology, Chiba University, Chiba, Japan

Y Awa, K Yamamoto, M Kinou, Department of Urology, Chiba University

T Yamanishi, Department of Urology, Dokkyo Medical College, Tochigi, Japan

Competing interests: none declared

\section{REFERENCES}

1 Onufrowicz B. Notes on the arrangement and function of the cell groups in the sacral region of the spinal cord. J Nerv Ment Dis 1899;26:498-504.

2 Mannen T, Iwata M, Toyokura $Y$, et al. The Onuf's nucleus and the external anal sphincter muscles in amyotrophic lateral sclerosis and Shy-Drager syndrome. Acta Neuropathol 1982;58:255-60.

3 Daniel SE. The neuropathology and neurochemistry of multiple system atrophy. In:Bannister R, Mathias CJ, editors. Autonomic failure, 3rd ed. Oxford: Oxford Medical Publications, 1992:564-85.

4 de Groat WC, Booth AM, Yoshimura N. Neurophysiology of micturition and its modification in animal models of human disease. In:Maggi CA, editor. The autonomic nervous system, vol.3. London: Harwood Academic Publisher, 1993:227-90.

5 Thor KB. Serotonin and norepinephrine involvement in efferent pathways to the urethral rhabdosphincter: implications for treating stress urinary incontinence. Urology 2003;62:3-9.

6 Sakakibara R, Nakazawa K, Shiba K, et al. Firing patterns of micturitionrelated neurons in the pontine storage centre in cats. Auton Neurosci Basic Clin 2002;99:24-30.

7 Vodusek DB. Sphincter EMG and differential diagnosis of multiple system atrophy. Mov Disord 2001;16:600-7.

8 Libelius R, Johansson F. Quantitative electromyography of the external anal sphincter in Parkinson's disease and multiple system atrophy. Muscle nerve 2000;23:1250-6.

9 Tison F, Arne P, Sourgen C, et al. The value of external anal sphincter electromyography for the diagnosis of multiple system atrophy. Mov Disord 2000;15:1148-57.

10 Nahm F, Freeman R. Sphincter electromyography and multiple system atrophy. Muscle Nerve 2003;28:18-26.

11 Sakuta M, Nakanishi T, Toyokura Y. Anal muscle electromyograms differ in amyotrophic lateral sclerosis and Shy-Drager syndrome. Neurology 1978;28:1289-93.

12 Beck RO, Betts CD, Fowler CJ. Genitourinary dysfunction in multiple system atrophy: clinical features and treatment in 62 cases. J Urol 1994; 151:1336-41

13 Rodi Z, Denislic M, Vodusek D. External anal sphincter electromyography in the differential diagnosis of parkinsonism. I Neurol Neurosurg Psychiatry 1996;60:460-1.

14 Palace J, Chandiramani VA, Fowler CJ. Value of sphincter electromyography in the diagnosis of multiple system atrophy. Muscle Nerve 1997;20:1396-403.

15 Sakakibara R, Hattori T, Uchiyama T, et al. Videourodynamic and sphincter motor unit potential analyses in Parkinson's disease and multiple system atrophy. J Neurol Neurosurg Psychiatry 2001;71:600-6. 
16 Gilman S, Low PA, Quinn N, et al. Consensus statement on the diagnosis of multiple system atrophy. J Auton Nerv Syst 1998;74:189-92.

17 Wenning GK, Colosimo C, Geser F, et al. Multiple system atrophy. Lancet Neurol 2004;3:93-103

18 Podner S, Fowler CJ. Sphincter electromyography in diagnosis of multiple system atrophy: technical issues. Muscle Nerve 2004;29:151-6.

19 Abrams P, Cardozo L, Fall M, et al. The standardization of terminology of lower urinary tract function: report from the standardization sub-committee of the international continence society. Neurourol Urodynam 2002:21:167-78.

20 Schafer W. Principles and clinical application of advanced urodynamic analysis of voiding dysfunction. Urol Clin North Am 1990;17:553-66.

21 Trouillas $\mathbf{P}$, Takayanagi T, Hallet $M$, et al. The Ataxia Neuropharmacology Committee of the World Federation of Neurology. International cooperative ataxia rating scale for pharmacological assessment of the cerebellar syndrome. J Neurol Sci 1997; 145:205-11.

22 Wenning GK, Ben-Schlomo $Y$, Magalhaes $M$, et al. Clinical features and natural history of multiple system atrophy. Brain 1994;117:835-45.

23 Hussain IF, Brady CM, Swinn MJ, et al. Treatment of erectile dysfunction with sildenafil citrate (Viagra) in parkinsonism due to Parkinson's disease or multiple system atrophy with observations on orthostatic hypotension. J Neurol Neurosurg Psychiatry 2001;71:371-4.

24 Sakakibara R, Odaka T, Uchiyama T, et al. Colonic transit time, sphincter EMG and rectoanal videomanometry in multiple system atrophy. Mov Disord 2004;19:924-9.

25 Sakakibara R, Hattori T, Kita K, et al. Stress-induced urinary incontinence in patients with spinocerebellar degeneration. J Neurol Neurosurg Psychiatry 1998;64:389-91.

\section{Clinical Evidence-Call for contributors}

Clinical Evidence is a regularly updated evidence-based journal available worldwide both as a paper version and on the internet. Clinical Evidence needs to recruit a number of new contributors. Contributors are healthcare professionals or epidemiologists with experience in evidence-based medicine and the ability to write in a concise and structured way.

Areas for which we are currently seeking contributors:

- Pregnancy and childbirth

- Endocrine disorders

- Palliative care

- Tropical diseases

We are also looking for contributors for existing topics. For full details on what these topics are please visit www. clinicalevidence.com/ceweb/contribute/index.jsp

However, we are always looking for others, so do not let this list discourage you.

Being a contributor involves:

- Selecting from a validated, screened search (performed by in-house Information Specialists) epidemiologically sound studies for inclusion.

- Documenting your decisions about which studies to include on an inclusion and exclusion form, which we keep on file.

- Writing the text to a highly structured template (about 1500-3000 words), using evidence from the final studies chosen, within 8-10 weeks of receiving the literature search.

- Working with Clinical Evidence editors to ensure that the final text meets epidemiological and style standards.

- Updating the text every 12 months using any new, sound evidence that becomes available. The Clinical Evidence in-house team will conduct the searches for contributors; your task is simply to filter out high quality studies and incorporate them in the existing text.

If you would like to become a contributor for Clinical Evidence or require more information about what this involves please send your contact details and a copy of your CV, clearly stating the clinical area you are interested in, to CECommissioning@bmigroup.com.

\section{Call for peer reviewers}

Clinical Evidence also needs to recruit a number of new peer reviewers specifically with an interest in the clinical areas stated above, and also others related to general practice. Peer reviewers are healthcare professionals or epidemiologists with experience in evidence-based medicine. As a peer reviewer you would be asked for your views on the clinical relevance, validity, and accessibility of specific topics within the journal, and their usefulness to the intended audience (international generalists and healthcare professionals, possibly with limited statistical knowledge). Topics are usually 1500-3000 words in length and we would ask you to review between 2-5 topics per year. The peer review process takes place throughout the year, and out turnaround time for each review is ideally 10-14 days.

If you are interested in becoming a peer reviewer for Clinical Evidence, please complete the peer review questionnaire at www. clinicalevidence.com/ceweb/contribute/peerreviewer.jsp 